Article

\title{
The Effects of Temperature on the Hydrothermal Synthesis of Hydroxyapatite-Zeolite Using Blast Furnace Slag
}

\author{
G.U. Ryu ${ }^{1}$, G.M. Kim ${ }^{2}$, Hammad R. Khalid ${ }^{3}$ and H.K. Lee ${ }^{1, *}$ \\ 1 Department of Civil and Environmental Engineering, Korea Advanced Institute of Science and Technology, \\ Guseong-dong, Yuseong-gu, Daejeon 305-701, Korea \\ 2 Center for Carbon Mineralization, Climate Change Mitigation and Sustainability Division, Korea Institute of \\ Geoscience and Mineral Resources, 124 Gwahak-ro, Yuseong-gu, Daejeon 34132, Korea \\ 3 Civil \& Environmental Engineering Department, King Fahd University of Petroleum \& Minerals, \\ Dhahran 31261, Saudi Arabia \\ * Correspondence: haengki@kaist.ac.kr; Tel.: +82-42-350-3623; Fax: +82-42-350-3610
}

Received: 4 June 2019; Accepted: 1 July 2019; Published: 2 July 2019

\begin{abstract}
Blast furnace slag, an industrial by-product, is emerging as a potential raw material to synthesize hydroxyapatite and zeolite. In this study, the effects of temperature on the hydrothermal synthesis of hydroxyapatite-zeolite from blast furnace slag were investigated. Specimens were synthesized at different temperatures (room temperature, 50, 90, 120, or $150^{\circ} \mathrm{C}$ ). The synthesized specimens were analyzed qualitatively and quantitatively via X-ray diffraction (XRD), Fourier transform infrared spectroscopy (FT-IR), BET/BJH, and scanning electron microscopy/energy dispersive using X-ray analysis (SEM/EDX). It was found that the hydroxyapatite phase was synthesized at all the reaction temperatures, while faujasite type zeolite appeared in the specimens synthesized at 90 and $120^{\circ} \mathrm{C}$. Moreover, faujasite was replaced by hydroxysodalite in the specimens synthesized at $150{ }^{\circ} \mathrm{C}$. Additionally, the crystals of the hydroxyapatite tended to become larger and total crystallinity increased as the reaction temperature increased.
\end{abstract}

Keywords: hydroxyapatite; zeolite; adsorbent; hydrothermal method; blast furnace slag

\section{Introduction}

Hydroxyapatite $\left(\mathrm{Ca}_{10}\left(\mathrm{PO}_{4}\right)_{6}(\mathrm{OH})_{2}\right)$ and zeolites (alumino-silicate materials represented by $\mathrm{M}_{\mathrm{m}}\left[\mathrm{Al}_{\mathrm{m}} \mathrm{Si}_{\mathrm{n}} \mathrm{O}_{2(\mathrm{~m}+\mathrm{n})}\right] \cdot \mathrm{H}_{2} \mathrm{O}$ where $\mathrm{M}$ represents alkali cations electrostatically bonded to the extra skeleton) have been used for various applications, i.e., adsorption and catalysis [1,2]. Specifically, they have been studied as adsorbents due to their high specific surface area and the ionic forces induced by the presence of exchangeable ions in their structures [3-5].

The adsorption performance of zeolites for cations is much higher than that for anions since the exchangeable ions in zeolites are usually alkali cations [6,7]. On the other hand, hydroxyapatite phases have high adsorption performance for both the cations and anions $[4,6,8,9]$. Cations are exchanged with calcium ions present in hydroxyapatite [6,10], while anions are exchanged with hydroxyl ions [4].

Hydroxyapatite and zeolites are normally synthesized by hydrothermal methods [11-13]. The reaction temperature for hydrothermal treatment is an important variable for the characteristics of the resulting products $[14,15]$. If the reaction temperature is not high enough, hydroxyapatite and zeolites cannot be synthesized, and it can result in a low specific surface area $[14,16]$. The formation rate of different crystals and the aspect ratio of hydroxyapatite crystals also get affected by the reaction temperature [17]. Similarly, an increase in the reaction temperature was favorable to synthesize zeolite crystals through a hydrothermal process [16]. 
In this study, blast furnace slag, which is a by-product of the iron industry, was used to synthesize hydroxyapatite and zeolite as main phases. Both of these materials were targeted, considering the fact that zeolites are efficient adsorbents for cations, and they can support hydroxyapatite to adsorb cations and anions simultaneously. Because of its low price and mineral composition, it has been used in various fields, especially the construction and environmental fields $[1,18,19]$. However, about $35 \%$ of the slag is still being wasted in Europe alone [20]. Owing to the chemical composition of slag, it can be used to synthesize hydroxyapatite and zeolites [12,21,22]. Recently, Khalid et al. [12] proposed a robust one-step hydrothermal treatment method to synthesize geopolymer-supported zeolite adsorbents using blast furnace slag and fly ash. Guo et al. [23] synthesized NaA-zeolite from blast furnace slag and studied their performance for removal of ammonium. Kuwahara et al. [1] and Li et al. [24] studied the effects of reaction time on the synthesis of zeolite and sodalite using Ti-bearing electric arc furnace slag.

Despite the high potential of slag utilization for the synthesis of these adsorbents, only two studies have been reported on the synthesis of hydroxyapatite using blast furnace slag [1,11]. Furthermore, it is known that the reaction temperature during hydrothermal treatment can significantly affect the resulting crystalline phases and total crystallinity $[14,15,25]$. Therefore, it is crucial to investigate the effects of the reaction temperature on the synthesis of hydroxyapatite using blast furnace slag, which has not been reported in the literature to the best of our knowledge. Hence, this study specifically focused on the investigation of effects of reaction temperature on the crystallinity, content, and dimension of synthesized hydroxyapatite and zeolite via the hydrothermal synthesis method. The specimens were synthesized at different reaction temperatures (room temperature, $50^{\circ} \mathrm{C}, 90^{\circ} \mathrm{C}, 120^{\circ} \mathrm{C}$, or $150{ }^{\circ} \mathrm{C}$ ). The characteristics of the specimens were investigated by X-ray diffraction (XRD), Fourier transform infrared spectroscopy (FT-IR), and scanning electron microscopy/energy dispersive using X-ray analysis (SEM/EDX), while microstructural characteristics were investigated via BET/BJH method.

\section{Materials and Methods}

\subsection{Materials}

The chemical composition of the blast furnace slag used in the present study was investigated by XRF; results are listed in Table 1 . The slag was mainly composed of $\mathrm{CaO}, \mathrm{Al}_{2} \mathrm{O}_{3}$, and $\mathrm{SiO}_{2}$ components, which are needed to synthesize hydroxyapatite and zeolites.

Table 1. Chemical components of blast furnace slag.

\begin{tabular}{cc}
\hline Compound & Proportion (wt.\%) \\
\hline $\mathrm{Al}_{2} \mathrm{O}_{3}$ & 7.50 \\
$\mathrm{SiO}_{2}$ & 18.20 \\
$\mathrm{SO}_{3}$ & 3.10 \\
$\mathrm{~K}_{2} \mathrm{O}$ & 0.76 \\
$\mathrm{CaO}$ & 67.60 \\
$\mathrm{TiO}$ & 0.95 \\
$\mathrm{MnO}_{2}$ & 0.44 \\
$\mathrm{Fe}_{2} \mathrm{O}_{3}$ & 1.0 \\
$\mathrm{NiO}$ & 0.04 \\
$\mathrm{CuO}$ & 0.046 \\
$\mathrm{SrO}$ & 0.019 \\
$\mathrm{ZrO}$ & 0.082 \\
\hline
\end{tabular}




\subsection{Test Methods}

The synthesis process for hydroxyapatite-zeolite consisted of three steps. In the first step, $25 \mathrm{~g}$ of slag and $100 \mathrm{~mL}$ of $1.77 \mathrm{M}$ phosphoric acid $\left(\mathrm{H}_{3} \mathrm{PO}_{4}\right.$, Samchun Pure Chemical, Pyeongtaek, Korea) solution were stirred at $350 \mathrm{rpm}$ using a magnetic stirrer at ambient temperature for $2 \mathrm{~h}$. In this step, the molar ratio of $\mathrm{Ca} / \mathrm{P}$ was fixed at 1.67 considering the theoretical $\mathrm{Ca} / \mathrm{P}$ ratio of hydroxyapatite is 1.67. In the second step, $350 \mathrm{~mL}$ of $2 \mathrm{M}$ sodium hydroxide ( $\mathrm{NaOH}$, Daejung Chemical \& Materials Co., LTD, Goryeong, Korea) solution was added to the prepared suspension. Mixtures were stirred at $450 \mathrm{rpm}$ for $4 \mathrm{~h}$ at their respective temperatures (such as room temperature, 50, 90, 120, or $150^{\circ} \mathrm{C}$ ) on the bottom of the beakers and specimens were denoted by HZ-R, HZ-50, HZ-90, HZ-120, and HZ-150, respectively. The mixture containers were fully covered with an aluminum foil to prevent the mixtures from water evaporation during stirring. In the last step, the prepared suspensions were transferred to sealed Teflon bottles and heated for $24 \mathrm{~h}$ in an oven again at their respective temperatures (i.e., room temperature, 50, 90, 120, or $150^{\circ} \mathrm{C}$ ). After the last step, white powders were obtained. The obtained powders were washed several times with distilled water, followed by filtration and drying.

X-ray diffraction (XRD), Fourier transform infrared spectroscopy (FT-IR) measurement, scanning electron microscopy/energy dispersive using X-ray analysis (SEM/EDX), and BET/BJH tests were conducted to characterize the crystallinity of the prepared specimens. The XRD analysis was conducted in a $5^{\circ}-65^{\circ} 2 \theta$ scan range at $0.2^{\circ} / \mathrm{min}$ scanning rate using PANalytical X'Pert PRO-MPD (DA107 at KBSI Daegu Center). Then, to investigate the quantities of hydroxyapatite and zeolites produced under the different synthesis conditions, the content of the crystalline phases was estimated from XRD diffraction patterns. It should be noted that the reference intensity ratio method, which is suitable method for zeolitic samples synthesized from blast furnace slag, was used to approximate the amount of crystalline phase of the samples [12,26]. SEM images were obtained to investigate the morphology of the crystalline phases in the synthesized specimens. FT-IR measurements $(6300 \mathrm{FV}$ and IRT5000 device, JASCO, Tokyo, Japan) were conducted in the range of $4000-450 \mathrm{~cm}^{-1}$ under a vacuum state using the KBR tablets in the transmission mode. The specific surface areas of the specimens were measured by $\mathrm{BET}$ test, and $\mathrm{BJH}$ pore volume tests were conducted to investigate the pore size distribution (PSD). EDX analysis was carried out to investigate the elemental composition of the reaction products. Before the EDX analysis, the samples were coated with Pt to enhance the conductivity of the samples, thereby increasing the visibility of the morphologies. It should be noted that the EDX spectra of the samples presented in this study excluded the intensity originated from the presence of $\mathrm{Pt}$ for a better comparison with other spectra.

\section{Results and Discussion}

\subsection{Crystalline Characteristics}

The XRD test results of the specimens synthesized at different reaction temperatures are shown in Figure 1. The XRD pattern of the blast furnace slag indicated that the slag included amorphous phases and crystalline peaks of anhydrite (PDF \#01-072-0916) and melilite (solid solution of gehlenite, PDF \#00-035-0755 and åkermanite, PDF \#01-074-0990) [1,12]. The XRD patterns of the specimens synthesized at room temperature and $50{ }^{\circ} \mathrm{C}$ showed broader peaks corresponding to hydroxyapatite (PDF \#98-003-4457), possibly due to low crystallinity. Alternatively, the peaks of the specimens synthesized at $90^{\circ} \mathrm{C}, 120^{\circ} \mathrm{C}$, and $150^{\circ} \mathrm{C}$ were quite sharp, showing well-developed crystals in these specimens as verified with SEM images. 
The XRD patterns of the specimens synthesized at room temperature and $50{ }^{\circ} \mathrm{C}$ showed only hydroxyapatite peaks (PDF \#98-003-4457), while those of the specimens synthesized at $90{ }^{\circ} \mathrm{C}$ and $120{ }^{\circ} \mathrm{C}$ showed faujasite (FAU) type zeolite (PDF \#98-008-5622) peaks as well. This indicated that zeolite phases can also be synthesized when the reaction temperature was $90^{\circ} \mathrm{C}$ or more. However, the XRD patterns of the specimens synthesized at $150^{\circ} \mathrm{C}$ showed the inclusion of hydroxysodalite (PDF \#98-016-3788) instead of faujasite because hydroxysodalite can be synthesized at a higher temperature than that to synthesize zeolite [27]. Hydroxysodalite is zeolite-like material, which also possess an affinity to adsorb cations such as heavy metals [12,28].

The crystallinity and quantitative content of the specimens synthesized at different reaction temperatures are listed in Table 2. It was observed that the crystallinity of the specimens fabricated at room temperature and $50^{\circ} \mathrm{C}$ was similar, meaning that reactivity was the same when the reaction temperature increased to $50^{\circ} \mathrm{C}$. The crystallinity of the specimens got doubled when the temperature increased to $90{ }^{\circ} \mathrm{C}$, compared to that of specimens synthesized at lower temperatures. Moreover, the crystallinity of specimens tended to increase with reaction temperature.

Compared to the content in specimens synthesized at reaction temperatures lower than $50{ }^{\circ} \mathrm{C}$, the content of the hydroxyapatite phase increased when the reaction temperature was more than $90{ }^{\circ} \mathrm{C}$. The content of the hydroxyapatite phase did not change significantly at reaction temperatures more than $90^{\circ} \mathrm{C}$. Meanwhile, the content of FAU type zeolite or hydroxysodalite increased as the reaction temperature increased. This means that zeolite or zeolite-like phases formed well when the reaction temperature increased beyond $90^{\circ} \mathrm{C}$. On the other hand, the reaction temperature did not significantly influence the quantity of formation of hydroxyapatite, although crystallinity does increase with reaction temperature.

The intensity of the peaks at 603 and $566 \mathrm{~cm}^{-1}$, representing $\mathrm{PO}_{4}{ }^{3-}$ groups in hydroxyapatite, increased with the increase in reaction temperature from room temperature to $90{ }^{\circ} \mathrm{C}$; this peak intensity slightly decreased with further increase in the reaction temperature [1]. This indicates the formation of zeolite crystals in the specimens synthesized above $90^{\circ} \mathrm{C}$. On the other hand, the peak intensities of the $\mathrm{SiO}_{4}{ }^{4-}$ and $\mathrm{PO}_{4}{ }^{3-}$ groups decreased with the increase of the reaction temperature to $90{ }^{\circ} \mathrm{C}$. Moreover, the intensities of the $\mathrm{CO}_{3}$ peaks $\left(1465-1468\right.$ and $\left.1417 \mathrm{~cm}^{-1}\right)$ and the dicalcium phosphate dehydrate peak $\left(875 \mathrm{~cm}^{-1}\right)$ were highest in the specimen synthesized at room temperature. This seems to be because dicalcium phosphate dehydrate was transformed into hydroxyapatite as the reaction temperature increased. The intensity of two water peaks at $3449-3438$ and $1640 \mathrm{~cm}^{-1}$ decreased with increasing reaction temperature due to the evaporation of water. It should be noted that the samples were oven dried at the identical temperature used for their synthesis, which resulted in the decrease in the water content in the samples synthesized at high temperatures.

Table 2. Crystallinity and quantitative content of the materials synthesized at the different reaction temperature.

\begin{tabular}{ccccc}
\hline $\begin{array}{c}\text { Reaction } \\
\text { Temperature }\end{array}$ & $\begin{array}{c}\text { Amorphous } \\
\text { Phase (\%) }\end{array}$ & Crystallinity (\%) & Phases & $\begin{array}{c}\text { Quantitative } \\
\text { Content (\%) }\end{array}$ \\
\hline Room temperature & 64 & 36 & Hydroxyapatite & 36 \\
$50^{\circ} \mathrm{C}$ & 66 & 34 & Hydroxyapatite & 34 \\
$90{ }^{\circ} \mathrm{C}$ & 37 & 63 & Hydroxyapatite & 50 \\
& & & FAU type zeolite & 13 \\
$120{ }^{\circ} \mathrm{C}$ & 43 & 57 & Hydroxyapatite & 50 \\
& & & FAU type zeolite & 7 \\
$150{ }^{\circ} \mathrm{C}$ & 30 & 71 & Hydroxyapatite & 46 \\
& & & Hydroxysodalite & 25 \\
\hline
\end{tabular}




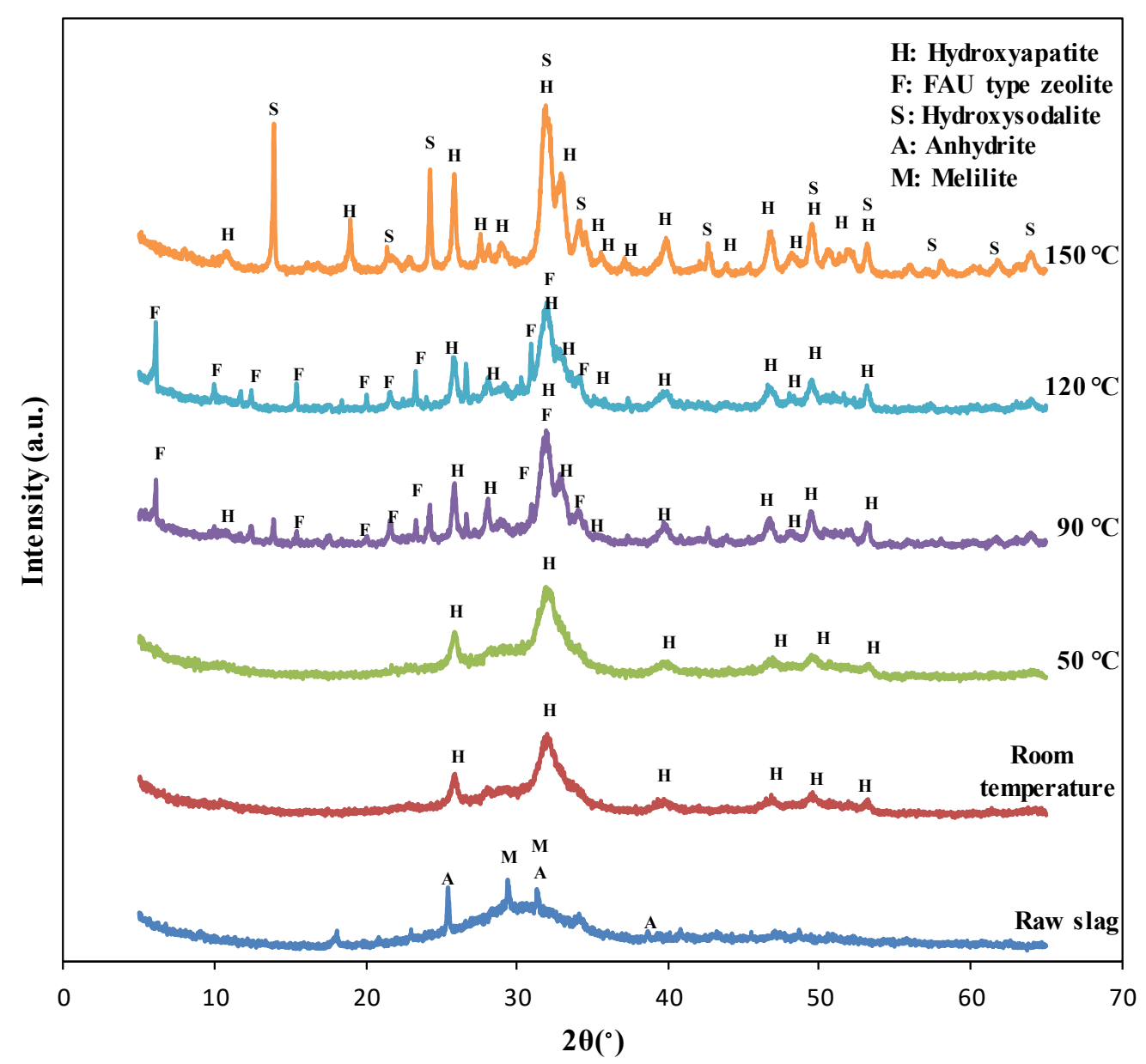

Figure 1. The XRD pattern of raw slag and the specimens synthesized at the different reaction temperature.

FT-IR spectra of the specimens synthesized at different reaction temperatures are presented in Figure 2. The spectra of the synthesized specimens showed clear absorption peaks at 1093, 1037, 963, 875,603 , and $566 \mathrm{~cm}^{-1}$, which are generally assigned to the vibration of the $\mathrm{PO}_{4}{ }^{3-}$ groups, although some parts of the $\mathrm{PO}_{4}{ }^{3-}$ absorption peaks are difficult to discern due to the superposition of the absorption bands with those of the silica group [1,29]. It should be noted that the silica matrix and the hydroxyapatite share many similar vibration modes [1]. This is due to the similarity of the $\mathrm{SiO}_{4}{ }^{4-}$ and $\mathrm{PO}_{4}{ }^{3-}$ tetrahedral units [1,29]. The vibration modes are $460 \mathrm{~cm}^{-1}$ ( $\mathrm{Si}-\mathrm{O}-\mathrm{Si}$ stretch/P-O bending), $963 \mathrm{~cm}^{-1}$ (Si-O/P-O symmetric stretch), $1037 \mathrm{~cm}^{-1}$ (Si-OH deformation vibration/vibration mode of $\mathrm{PO}_{4}{ }^{3-}$ group), and $1093 \mathrm{~cm}^{-1}$ (Si-O/P-O stretch) [1,29]. However, the four peaks at $1465-1468,1417$, 603 , and $565 \mathrm{~cm}^{-1}$ are distinctly indicative of hydroxyapatite [1]. The peaks at $1465-1468$ and $1417 \mathrm{~cm}^{-1}$ are assigned to the carbonate $\mathrm{CO}_{3}{ }^{2-}$ groups replacing the $\mathrm{PO}_{4}{ }^{3-}$ in the hydroxyapatite. The peaks of the carbonate groups usually appear in all the hydroxyapatite synthesized in the air [30]. The last two peaks at 603 and $566 \mathrm{~cm}^{-1}$ can represent hydroxyapatite formation [1]. The small peak at $875 \mathrm{~cm}^{-1}$ is due to $\mathrm{HPO}_{4}{ }^{2-}$ groups from the reactant, which is dicalcium phosphate dehydrate $\left(\mathrm{CaHPO}_{4} \cdot 2 \mathrm{H}_{2} \mathrm{O}\right)$, synthesized from blast furnace slag mixed with phosphoric acid without $\mathrm{NaOH}$ solution $[1,31]$. On the other hand, the left two peaks at 3449-3438 and $1640 \mathrm{~cm}^{-1}$ represent water [32]. 


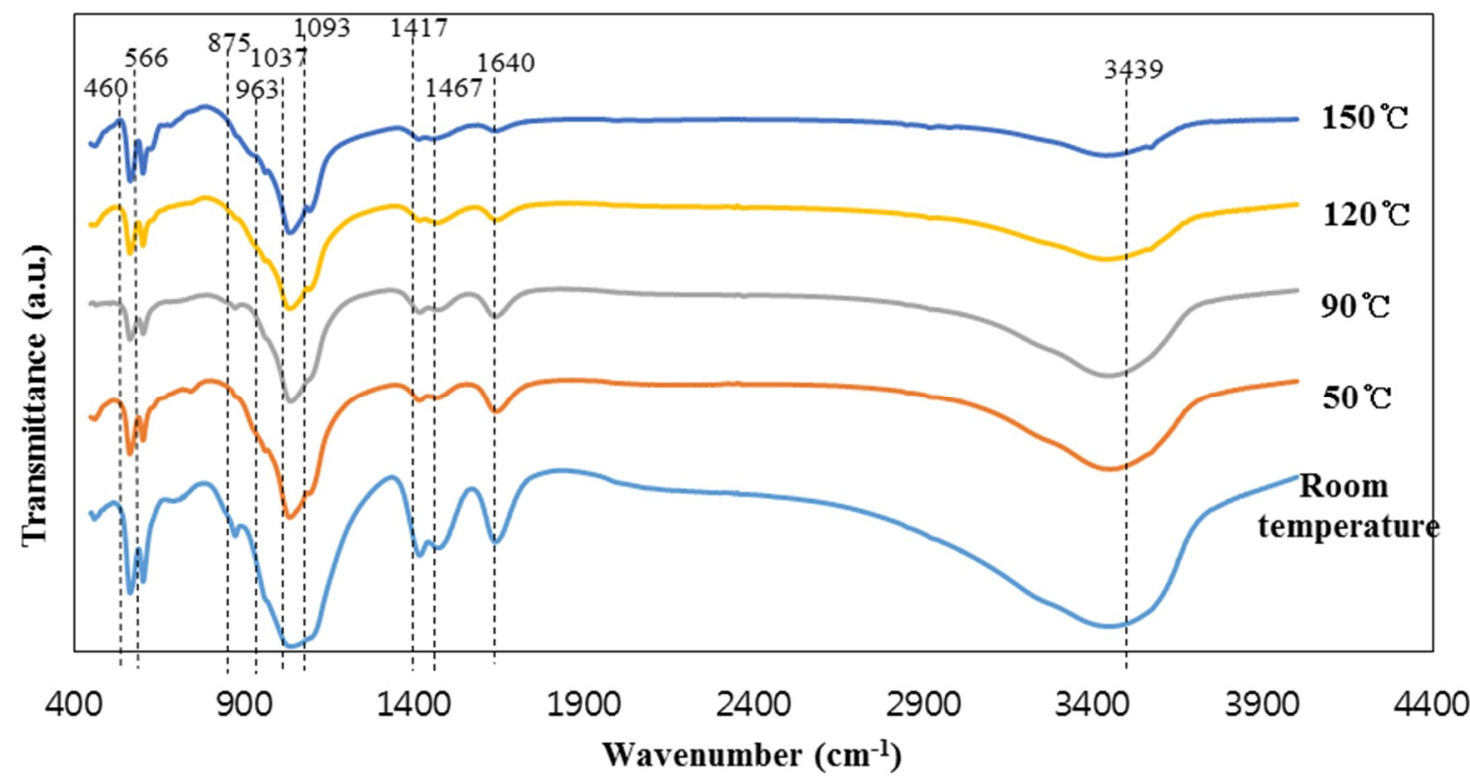

Figure 2. The FT-IR spectra of the materials synthesized at the different reaction temperature.

\subsection{Microstructural Characteristics}

$\mathrm{BET} / \mathrm{BJH}$ test was conducted to investigate the specific surface area and microstructure of the specimens synthesized in this study. The specific surface area and pore characteristics of specimens are presented in Table 3 . The test results show that the specific surface area of the specimens synthesized at $50^{\circ} \mathrm{C}$ decreased compared to the specimens synthesized at room temperature. However, the specimens synthesized at $90{ }^{\circ} \mathrm{C}$ had the largest specific surface area because FAU type zeolite formed, while the specific surface area of the specimens synthesized at $120^{\circ} \mathrm{C}$ and $150{ }^{\circ} \mathrm{C}$ decreased continuously. This tendency is similar for the cumulative volume of pores from BJH adsorption. The decrease in the specific surface area of the synthesized specimens was possibly attributable to changes in content among hydroxyapatite, FAU type zeolite, and hydroxysodalite (see Table 2). The reason that the specific surface area of the specimens synthesized at $150{ }^{\circ} \mathrm{C}$ was lowest seems to be the formation of hydroxysodalite, which has lower specific surface area than that of the FAU type zeolite [12]. The BJH adsorption average pore diameter of the specimens synthesized at $120^{\circ} \mathrm{C}$ was the largest and that of the specimens synthesized at $50{ }^{\circ} \mathrm{C}$ was the smallest. These results seem to be due to differences in pore distribution of specimens synthesized at different reaction temperatures. Overall the specific surface area decreases as the temperature increases within the temperature range for producing the same crystal phase $[33,34]$. Moreover, the higher specific surface area can help to improve the adsorption capacity $[35,36]$.

Table 3. BET/BJH results of the materials synthesized at the different reaction temperature.

\begin{tabular}{cccccc}
\hline Reaction Temperature & $\begin{array}{c}\text { Room } \\
\text { Temperature }\end{array}$ & $\mathbf{5 0}{ }^{\circ} \mathbf{C}$ & $\mathbf{9 0}{ }^{\circ} \mathbf{C}$ & $\mathbf{1 2 0}{ }^{\circ} \mathbf{C}$ & $\mathbf{1 5 0}{ }^{\circ} \mathbf{C}$ \\
\hline Specific surface area $\left(\mathrm{m}^{2} / \mathrm{g}\right)$ & 84.84 & 69.35 & 98.74 & 78.57 & 51.34 \\
\hline $\begin{array}{c}\text { BJH Adsorption cumulative } \\
\text { volume of pores }\left(\mathrm{cm}^{3} / \mathrm{g}\right)\end{array}$ & 0.28 & 0.19 & 0.30 & 0.19 & 0.18 \\
\hline $\begin{array}{c}\text { BJH Adsorption average pore } \\
\text { diameter }(\mathrm{nm})\end{array}$ & 11.30 & 9.44 & 9.96 & 13.37 & 13.18 \\
\hline
\end{tabular}


The pore size distributions (PSD) of the specimens are plotted in Figure 3. For all the specimens, the pores were mostly distributed in the mesoporous range $(10 \mathrm{~nm}$ and $30 \mathrm{~nm})$. The specimens synthesized at room temperature and $90^{\circ} \mathrm{C}$ have a relatively high specific surface area and, compared to the other specimens, were found to contain a large number of pores with sizes between 10 and $30 \mathrm{~nm}$. This pore size range is encouraging because mesoporous materials are advantageous for adsorbing contaminants $[12,21,37]$. However, it should be noted that the contaminant adsorption capacity of the hydroxyapatite-zeolite could be higher than that of pure hydroxyapatite because zeolite has the higher specific surface area and adsorption capacity than those of hydroxyapatite, implying that zeolite, which can only adsorb cations, and hydroxyapatite can complement each other [1,11].

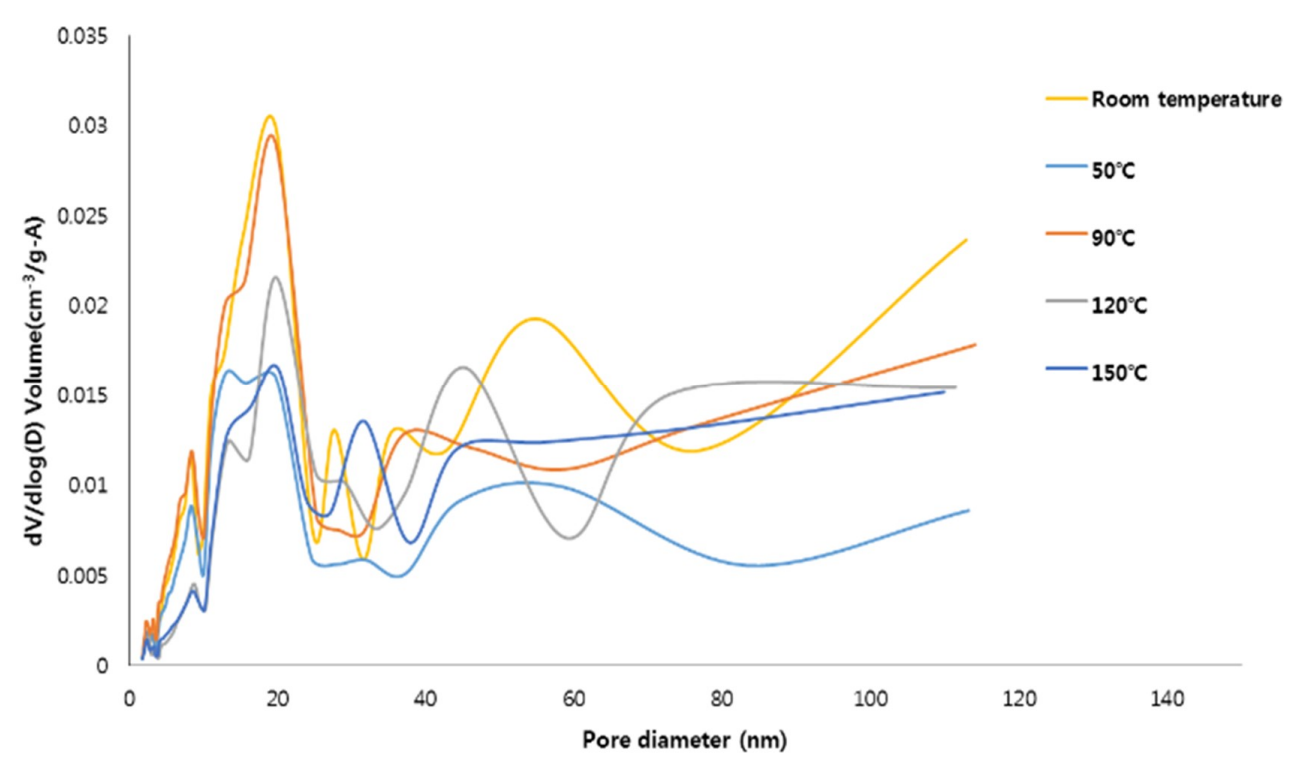

Figure 3. The pore distribution of the materials synthesized at the different reaction temperature.

\subsection{SEM/EDX Test}

SEM images of crystals are shown in Figure 4. The hydroxyapatite crystals in the specimens synthesized at $120^{\circ} \mathrm{C}$ look like irregular clusters of needles [38] (Figure 4a). The size of the hydroxyapatite crystals was about $300 \mu \mathrm{m}$. The crystals with a size of approximately $120 \mu \mathrm{m}$ and hierarchical pore system are FAU type zeolite, which was observed in the identical specimens [39] (Figure 4b). Hydroxysodalite, which had spherical crystals that aggregate to form agglomerates with a size of approximately $40 \mu \mathrm{m}$, was observed in the specimens synthesized at $150{ }^{\circ} \mathrm{C}$, as shown in Figure 4c [28].

The EDX test results for each crystal are presented in Figure 5. The $(\mathrm{Ca}+\mathrm{Mg}+\mathrm{Na}) / \mathrm{P}$ molar ratio of the hydroxyapatite crystals, shown in Figure 5a, corresponding to a stoichiometric composition of 1.68, which means that $\mathrm{Ca}$ is partially substituted with $\mathrm{Mg}$ and $\mathrm{Na}$ components [1]. From an elemental analysis, the FAU type zeolite appears to be a Na-type X-zeolite having a molar ratio of $\mathrm{SiO}_{2} / \mathrm{Al}_{2} \mathrm{O}_{3}=2.47$. The $\mathrm{SiO}_{2} / \mathrm{Al}_{2} \mathrm{O}_{3}$ ratio of the hydroxyapatite crystals (4.24) was higher than that of the FAU type zeolite crystals. This indicates the $\mathrm{Si}^{4+}$ and $\mathrm{Al}^{3+}$ ions bound to the hydroxyapatite lattice during hydroxyapatite formation [1]. 


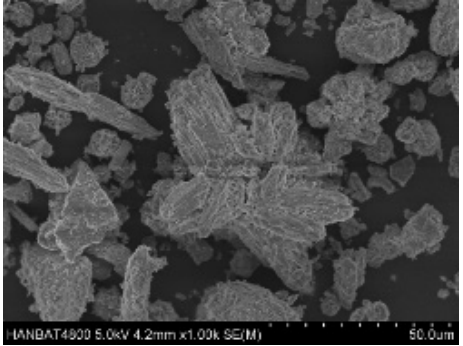

(a)

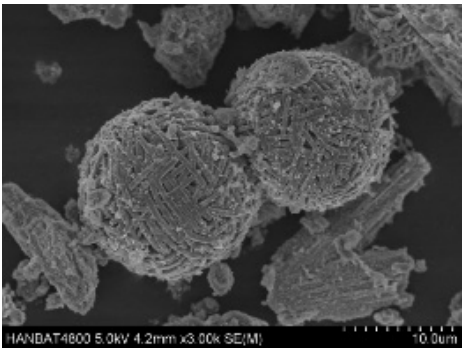

(b)

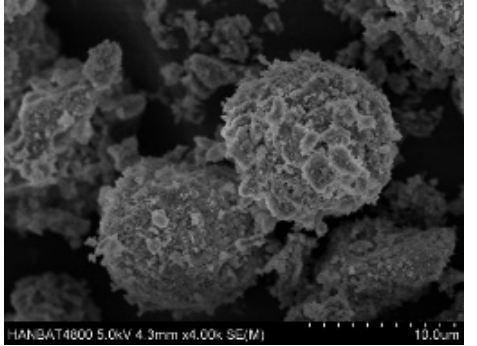

(c)

Figure 4. SEM images of (a) hydroxyapatite, (b) FAU type zeolite, and (c) hydroxysodalite.
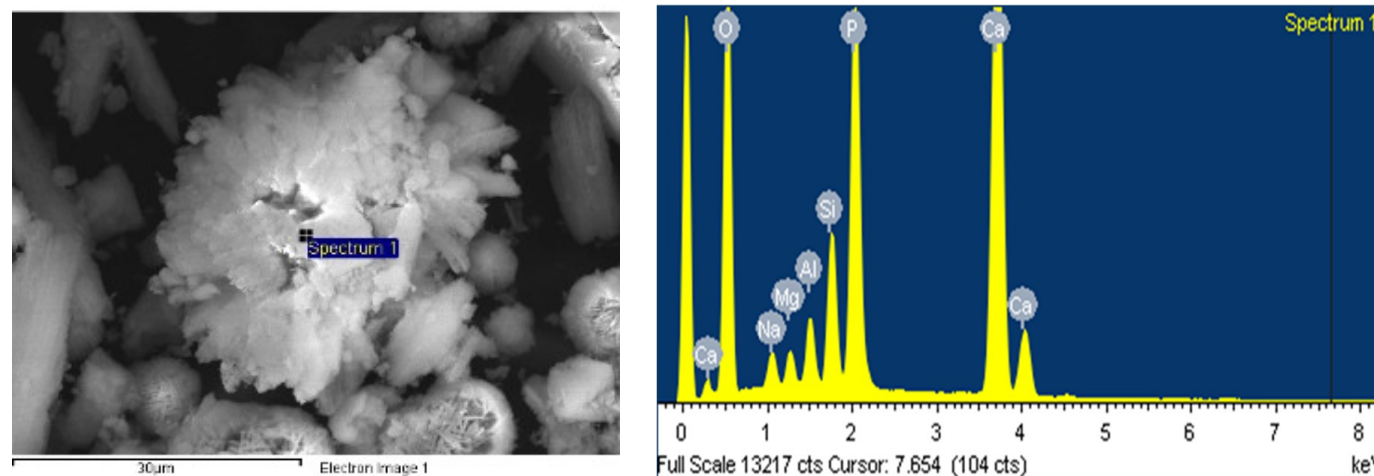

(a)
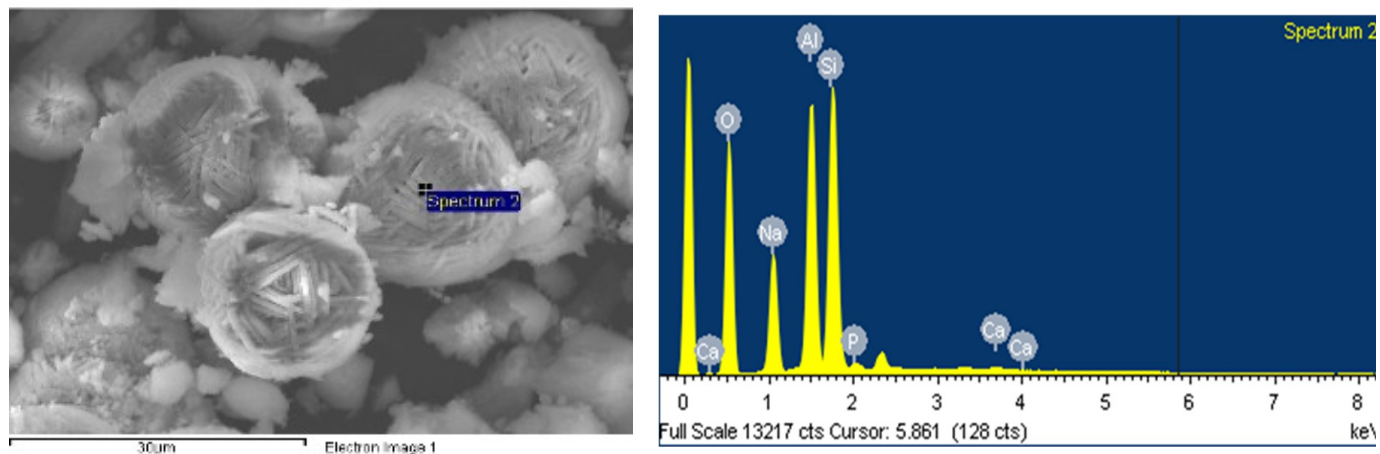

(b)
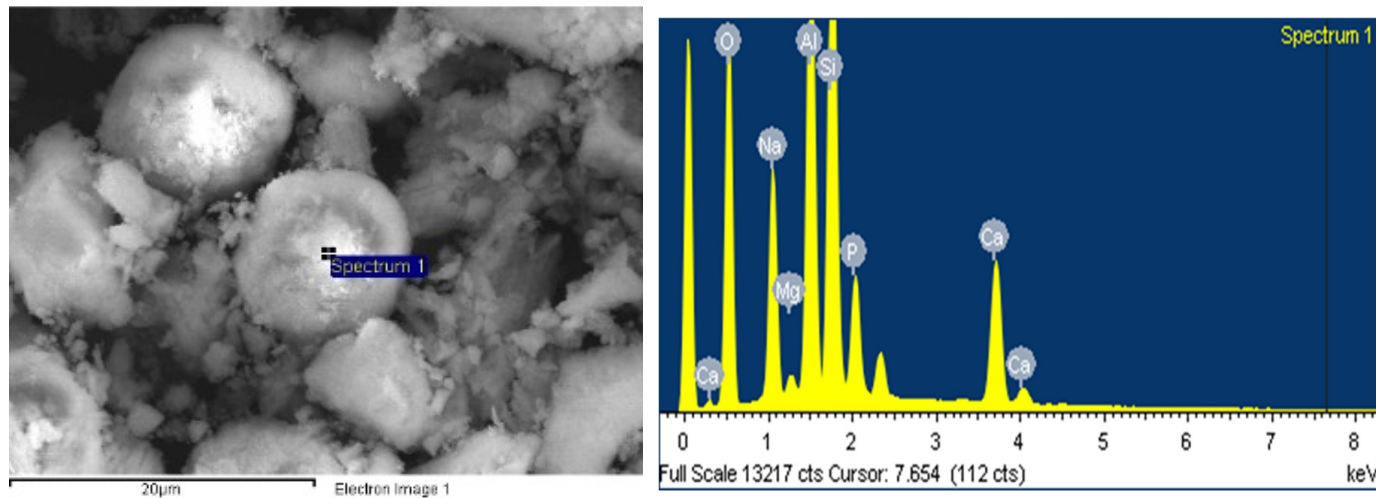

(c)

Figure 5. EDX spectra of (a) hydroxyapatite, (b) FAU type zeolite, and (c) hydroxysodalite.

Lastly, the effects of reaction temperature on hydroxyapatite are shown in Figure 6. As the reaction temperature increased, the crystallinity and the size of the hydroxyapatite crystals tended to increase. The hydroxyapatite crystals synthesized at room temperature were about $500 \mathrm{~nm}$ in size, and the 
crystallinity seemed to be low. The hydroxyapatite crystals synthesized at $50{ }^{\circ} \mathrm{C}$ showed good growth compared to those synthesized at room temperature; needle-like shapes of specimens can be confirmed in the SEM images $[40,41]$. In the specimens synthesized at $90^{\circ} \mathrm{C}$, hydroxyapatite crystals had irregular cluster needle shapes, which is similar to the shape of the specimen synthesized at $120^{\circ} \mathrm{C}$, but smaller. The growth of the hydroxyapatite crystal size, as the reaction temperature increase, is consistent with other studies $[33,42,43]$. This is the reason why the specific surface area decreases as the temperature increases with the same crystal phase (see Table 3) [33,42].

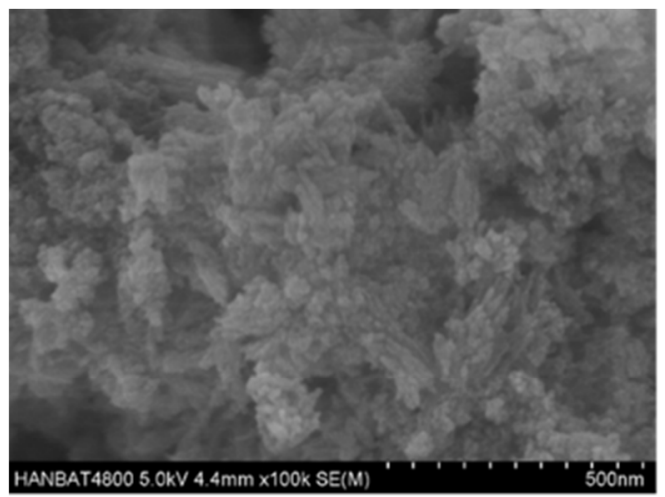

Room temperature

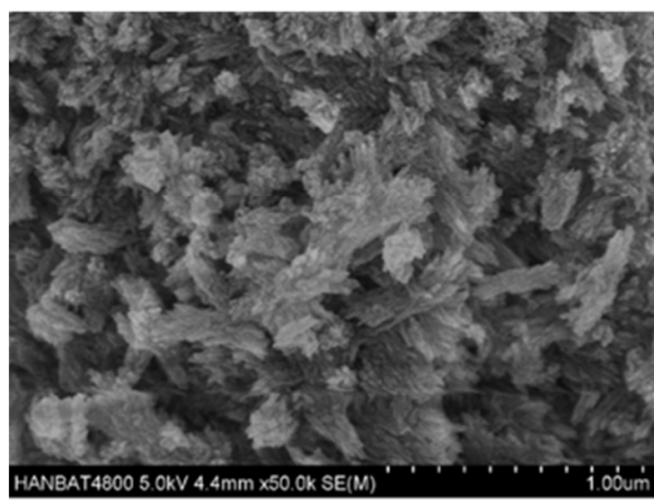

$90^{\circ} \mathrm{C}$
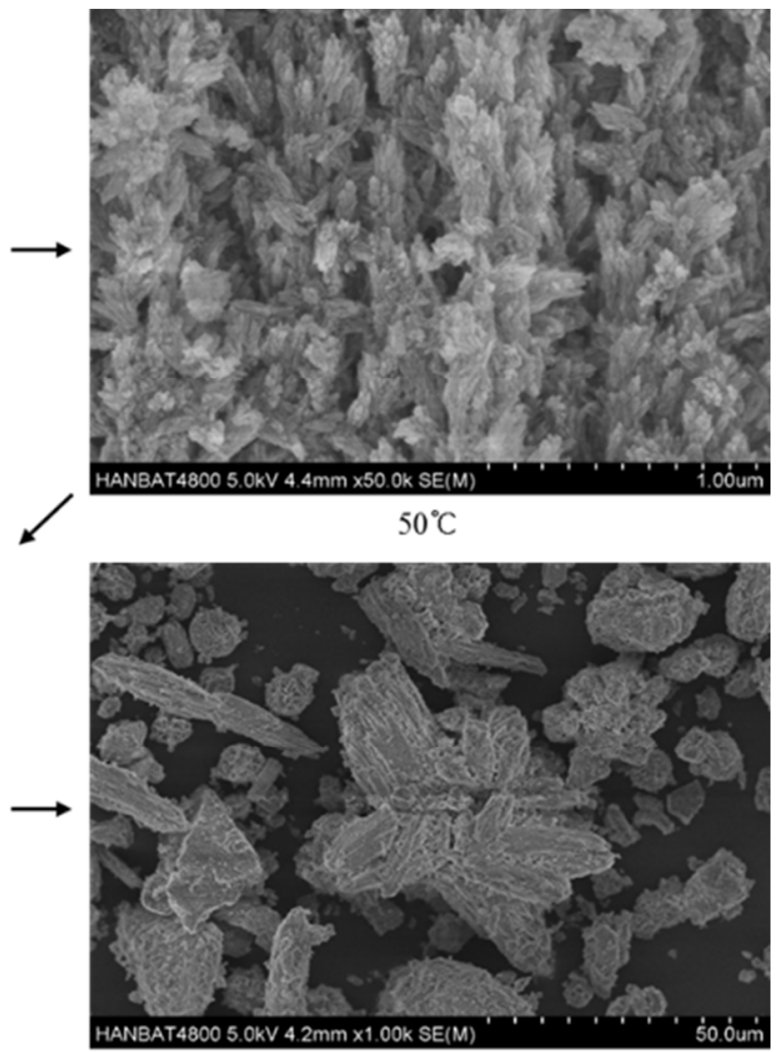

$120^{\circ} \mathrm{C}$

Figure 6. Hydroxyapatite crystalline synthesized at different reaction temperature.

\section{Concluding Remarks}

In this study, the effects of reaction temperature on the synthesis of hydroxyapatite-zeolite from blast furnace slag by the hydrothermal method were investigated. Specimens were synthesized at five different reaction temperatures; followed by characterization through XRD, FT-IR, BET/BJH, and SEM/EDX analyses. The results presented in this study will contribute to broadening the knowledge of physicochemical characteristics of hydroxyapatite-zeolite materials synthesized from blast furnace slag, especially with regard to the reaction temperature. The findings from the present study can be summarized as follows.

1. Up to $50{ }^{\circ} \mathrm{C}$ reaction temperature, only hydroxyapatite was synthesized, while FAU type zeolite was formed at $90^{\circ} \mathrm{C}$ and $120^{\circ} \mathrm{C}$ in addition to hydroxyapatite. With further increase in temperature to $150^{\circ} \mathrm{C}$, hydroxysodalite was synthesized instead of FAU type zeolite along with hydroxyapatite.

2. As the reaction temperature increased, the crystallinity of the specimens tended to increase, and the content of crystalline phases also changed. The content of hydroxyapatite increased with temperature up to $90^{\circ} \mathrm{C}$, while no change was observed with further increment in the temperature. 
3. The specimens synthesized at $90^{\circ} \mathrm{C}$ had the highest specific surface area of $98.7 \mathrm{~m}^{2} / \mathrm{g}$, and the specimen synthesized at $150^{\circ} \mathrm{C}$ had the lowest specific surface area (51.3) potentially due to the formation of the hydroxysodalite, which has a relatively small specific surface area.

4. The pore size distributions of the specimens prepared at room temperature and $90{ }^{\circ} \mathrm{C}$ were largely in the mesoporous range, which is advantageous for adsorbing contaminants.

5. SEM test results showed that hydroxyapatite and FAU type zeolite phases could be clearly observed at the reaction temperature of $120^{\circ} \mathrm{C}$, while hydroxysodalite phase was observed at the reaction temperature of $150^{\circ} \mathrm{C}$ instead of FAU type zeolite.

Hence, it can be concluded that $90{ }^{\circ} \mathrm{C}$ was the most optimized reaction temperature to synthesize the hydroxyapatite-zeolite using blast furnace slag by the hydrothermal treatment. The results of this study indicate the potential of the synthesized materials to be used as absorbents to remove contaminants $[6,7,10,35,38]$. However, further study will be needed to investigate the contaminant adsorption capacity of hydroxyapatite-zeolite synthesized by the hydrothermal method.

\section{Patents}

This section is not mandatory, but may be added if there are patents resulting from the work reported in this manuscript.

Author Contributions: Conceptualization, G.M.K.; methodology, G.M.K. and G.U.R.; validation, G.U.R.; formal analysis G.U.R.; investigation, G.U.R.; writing—original draft preparation, G.U.R.; writing—review and editing, G.U.R., G.M.K., H.R.K., H.K.L.; supervision, H.K.L.; project administration, H.K.L.; funding acquisition, H.K.L.

Funding: This research was supported by a grant (18CTAP-C143331-01) from Technology Advancement Research Program (TARP) Program funded by Ministry of Land, Infrastructure and Transport of Korean government.

Conflicts of Interest: The authors declare no conflict of interest.

\section{References}

1. Kuwahara, Y.; Ohmichi, T.; Kamegawa, T.; Mori, K.; Yamashita, H. Synthesis of Hydroxyapatite-Zeolite Composite Material from Disposed Steel Slag and Investigation of Its Structural and Physicochemical Characteristics. Chem. Lett. 2009, 38, 626-627. [CrossRef]

2. Saito, M.; Maruoka, A.; Mori, T.; Sugano, N.; Hino, K. Experimental studies on a new bioactive bone cement: Hydroxyapatite composite resin. Biomaterials 1994, 15, 156-160. [CrossRef]

3. Roy, D.M.; GLinnehan, S.K. Hydroxyapatite formed from coral skeletal carbonate by hydrothermal exchange. Nature 1974, 247, 220-222. [CrossRef]

4. He, J.; Zhang, K.; Wu, S.; Cai, X.; Chen, K.; Li, Y.; Sun, B.; Jia, Y.; Meng, F.; Jin, Z.; et al. Performance of novel hydroxyapatite nanowires in treatment of fluoride contaminated water. J. Hazard. Mater. 2016, 303, 119-130. [CrossRef]

5. Kendrick, E.; Dann, S. Synthesis, properties and structure of ion exchanged hydrosodalite. J. Solid State Chem. 2004, 177, 1513-1519. [CrossRef]

6. Gómez del Río, J.A.; Morando, P.J.; Cicerone, D.S. Natural materials for treatment of industrial effluents: Comparative study of the retention of $\mathrm{Cd}, \mathrm{Zn}$ and $\mathrm{Co}$ by calcite and hydroxyapatite. Part I: Batch experiments. J. Environ. Manag. 2004, 71, 169-177. [CrossRef]

7. Lee, N.K.; Khalid, H.R.; Lee, H.K. Adsorption characteristics of cesium onto mesoporous geopolymers containing nano-crystalline zeolites. Microporous Mesoporous Mater. 2017, 242, 238-244. [CrossRef]

8. Corami, A.; Mignardi, S.; Ferrini, V. Copper and zinc decontamination from single- and binary-metal solutions using hydroxyapatite. J. Hazard. Mater. 2007, 146, 164-170. [CrossRef]

9. Choi, S.; Jeong, Y. The removal of heavy metals in aqueous solution by hydroxyapatite/cellulose composite. Fibers Polym. 2008, 9, 267-270. [CrossRef]

10. Bailliez, S.; Nzihou, A.; Bèche, E.; Flamant, G. Removal of lead (Pb) by hydroxyapatite sorbent. Process Saf. Environ. Prot. 2004, 82, 175-180. [CrossRef] 
11. Kuwahara, Y.; Ohmichi, T.; Kamegawa, T.; Mori, K.; Yamashita, H. A novel synthetic route to hydroxyapatite-zeolite composite material from steel slag: Investigation of synthesis mechanism and evaluation of physicochemical properties. J. Mater. Chem. 2009, 19, 7263-7272. [CrossRef]

12. Khalid, H.R.; Lee, N.K.; Park, S.M.; Abbas, N.; Lee, H.K. Synthesis of geopolymer-supported zeolites via robust one-step method and their adsorption potential. J. Hazard. Mater. 2018, 353, 522-533. [CrossRef] [PubMed]

13. Yao, G.; Lei, J.; Zhang, X.; Sun, Z.; Zheng, S. One-step hydrothermal synthesis of zeolite X powder from natural low-grade diatomite. Materials (Basel) 2018, 11, 906. [CrossRef] [PubMed]

14. Wang, Y.; Zhang, S.; Wei, K.; Zhao, N.; Chen, J.; Wang, X. Hydrothermal synthesis of hydroxyapatite nanopowders using cationic surfactant as a template. Mater. Lett. 2006, 60, 1484-1487. [CrossRef]

15. Ma, M.G. Hierarchically nanostructured hydroxyapatite: Hydrothermal synthesis, morphology control, growth mechanism, and biological activity. Int. J. Nanomed. 2012, 7, 1781-1791. [CrossRef] [PubMed]

16. Querol, X.; Moreno, N.; Alastuey, A.; Herna'ndez, E.; Lo'pez-Soler, A.; Plana, F. Synthesis of zeolites from coal fly ash: an overview. Int. J. Coal Geol. 2002, 50, 413-423. [CrossRef]

17. Ren, F.; Ding, Y.; Ge, X.; Lu, X.; Wang, K.; Leng, Y. Growth of one-dimensional single-crystalline hydroxyapatite nanorods. J. Cryst. Growth 2012, 349, 75-82. [CrossRef]

18. Tsakiridis, P.E.; Papadimitriou, G.D.; Tsivilis, S.; Koroneos, C. Utilization of steel slag for Portland cement clinker production. J. Hazard. Mater. 2008, 152, 805-811. [CrossRef]

19. Kim, G.M.; Khalid, H.R.; Kim, H.J.; Lee, H.K. Alkali activated slag pastes with surface-modified blast furnace slag. Cem. Concr. Compos. 2017, 76, 39-47. [CrossRef]

20. Motz, H.; Geiseler, J. Products of steel slags an opportunity to save natural resources. Waste Manag. 2001, 21, 285-293. [CrossRef]

21. Lee, N.K.; Khalid, H.R.; Lee, H.K. Synthesis of mesoporous geopolymers containing zeolite phases by a hydrothermal treatment. Microporous Mesoporous Mater. 2016, 229, 22-30. [CrossRef]

22. Khalid, H.R.; Lee, N.K.; Choudhry, I.; Wang, Z.; Lee, H.K. Evolution of zeolite crystals in geopolymer-supported zeolites: Effects of composition of starting materials. Mater. Lett. 2019, 239, 33-36. [CrossRef]

23. Guo, H.; Tang, L.; Yan, B.; Wan, K.; Li, P. NaA zeolite derived from blast furnace slag: Its application for ammonium removal. Water Sci. Technol. 2017, 76, 1140-1149. [CrossRef] [PubMed]

24. Li, Y.; Peng, T.; Man, W.; Ju, L.; Zheng, F.; Zhang, M.; Guo, M. Hydrothermal synthesis of mixtures of NaA zeolite and sodalite from Ti-bearing electric arc furnace slag. RSC Adv. 2016, 6, 8358-8366. [CrossRef]

25. Huang, L.Y.; Xu, K.W.; Lu, J. A study of the process and kinetics of electrochemical deposition and the hydrothermal synthesis of hydroxyapatite coatings. J. Mater. Sci. Mater. Med. 2000, 11, 667-673. [CrossRef]

26. Jenkins, R.; Snyder, R.L. Introduction to X-Ray Powder Diffractometry; Wiley: New York, NY, USA, 1996.

27. Belviso, C.; Cavalcante, F.; Fiore, S. Synthesis of zeolite from Italian coal fly ash: Differences in crystallization temperature using seawater instead of distilled water. Waste Manag. 2010, 30, 839-847. [CrossRef] [PubMed]

28. Golbad, S.; Khoshnoud, P.; Abu-Zahra, N. Hydrothermal synthesis of hydroxy sodalite from fly ash for the removal of lead ions from water. Int. J. Environ. Sci. Technol. 2017, 14, 135-142. [CrossRef]

29. Bianco, A.; Cacciotti, I.; Lombardi, M.; Montanaro, L. Si-substituted hydroxyapatite nanopowders- Synthesis, thermal stability and sinterability. Mater. Res. Bull. 2009, 44, 345-354. [CrossRef]

30. Suchanek, W.L.; Byrappa, K.; Shuk, P.; Riman, R.E.; Janas, V.F.; Tenhuisen, K.S. Mechanochemicalhydrothermal synthesis of calcium phosphate powders with coupled magnesium and carbonate substitution. J. Solid State Chem. 2004, 177, 793-799. [CrossRef]

31. Clarkin, O.M.; Towler, M.R.; Insley, G.M.; Murphy, M.E. Phase transformations of calcium phosphates formed in wet field environments. J. Mater. Sci. 2007, 42, 8357-8362. [CrossRef]

32. Ludvigsson, M.; Lindgren, J.; Tegenfeldt, J. FTIR study of water in cast Nafion films. Electrochim. Acta 2000, 45, 2267-2271. [CrossRef]

33. Loo, S.C.J.; Siew, Y.E.; Ho, S.; Boey, F.Y.C.; Ma, J. Synthesis and hydrothermal treatment of nanostructured hydroxyapatite of controllable sizes. J. Mater. Sci. Mater. Med. 2008, 19, 1389-1397. [CrossRef] [PubMed]

34. Kothapalli, C.; Wei, M.; Vasiliev, A.; Shaw, M.T. Influence of temperature and concentration on the sintering behavior and mechanical properties of hydroxyapatite. Acta Mater. 2004, 52, 5655-5663. [CrossRef]

35. Fontes, M.P.F.; Weed, S.B. Phosphate adsorption by clays from Brazilian Oxisols: Relationships with specific surface area and mineralogy. Geoderma 1996, 72, 37-51. [CrossRef] 
36. Chiang, P.C.; You, J.H. Use of sewage sludge for manufacturing adsorbents. Can. J. Chem. Eng. 1987, 65, 922-927. [CrossRef]

37. Zhang, Z.; Provis, J.L.; Reid, A.; Wang, H. Fly ash-based geopolymers: The relationship between composition, pore structure and efflorescence. Cem. Concr. Res. 2014, 64, 30-41. [CrossRef]

38. Yang, L.X.; Yin, J.J.; Wang, L.L.; Xing, G.X.; Yin, P.; Liu, Q.W. Hydrothermal synthesis of hierarchical hydroxyapatite: Preparation, growth mechanism and drug release property. Ceram. Int. 2012, 38, 495-502. [CrossRef]

39. Rioland, G.; Albrecht, S.; Josien, L.; Vidal, L.; Daou, T.J. The influence of the nature of organosilane surfactants and their concentration on the formation of hierarchical FAU-type zeolite nanosheets. New J. Chem. 2015, 39, 2675-2681. [CrossRef]

40. Smolen, D.; Chudoba, T.; Malka, I.; Kedzierska, A.; Lojkowski, W.; Swieszkowski, W.; Kurzydlowski, K.J.; Kolodziejczyk-Mierzynska, M.; Lewandowska-Szumiel, M. Highly biocompatible, nanocrystalline hydroxyapatite synthesized in a solvothermal process driven by high energy density microwave radiation. Int. J. Nanomed. 2013, 8, 653-668. [CrossRef] [PubMed]

41. Chen, S.; Zhu, Z.; Zhu, J.; Zhang, J.; Shi, Y.; Yu, K.; Wang, W.; Wang, X.; Feng, X.; Luo, L.; et al. Hydroxyapatite coating on porous silicon substrate obtained by precipitation process. Appl. Surf. Sci. 2004, 230, 418-424.

42. Chen, C.W.; Oakes, C.S.; Byrappa, K.; Riman, R.E.; Brown, K.; TenHuisen, K.S.; Janas, V.F. Synthesis, characterization, and dispersion properties of hydroxyapatite prepared by mechanochemical-hydrothermal methods. J. Mater. Chem. 2004, 14, 2425-2432. [CrossRef]

43. Wang, A.; Yin, H.; Liu, D.; Wu, H.; Ren, M.; Jiang, T.; Cheng, X.; Xu, Y. Size-controlled synthesis of hydroxyapatite nanorods in the presence of organic modifiers. Mater. Lett. 2007, 61, 2084-2088. [CrossRef]

(C) 2019 by the authors. Licensee MDPI, Basel, Switzerland. This article is an open access article distributed under the terms and conditions of the Creative Commons Attribution (CC BY) license (http://creativecommons.org/licenses/by/4.0/). 